\title{
OS DESAFIOS TEÓRICO-METODOLÓGICOS DA INVESTIGAÇÃO ETNOGRÁFICA EM UM CURSO DE EDUCAÇÃO FÍSICA
}

\author{
THEORETICAL-METHODOLOGICAL CHALLENGES OF ETHNOGRAPHIC \\ RESEARCH IN A PHYSICAL EDUCATION SCHOOL
}

\author{
LOS DESAFIOS TEÓRICO-METODOLÓGICOS DE LA INVESTIGACIÓN \\ ETNOGRÁFICA EN UN CURSO DE EDUCACIÓN FÍSICA
}

\author{
Cláudia Aleixo Alves*, Zenólia Christina Campos Figueiredo*
}

Palavras chave:

Etnografia.

Currículo.

Educação Física.

\begin{abstract}
Resumo: O presente artigo busca narrar a trajetória das decisões teórico-metodológicas e dos desafios acerca do uso da etnografia em um estudo que se desenvolveu no cotidiano curricular de um curso de Educação Física. Destacam-se o processo que envolveu os procedimentos para realização do estudo; as implicações da escolha da etnografia como referencial teórico metodológico; a iniciação à etnografia e o processo de pesquisa de campo resultante de um ano letivo de acompanhamento da rotina curricular. Conclui-se que a etnografia potencializa o entendimento do currículo enquanto construção social.
\end{abstract}

Keywords:

Ethnography.

Curriculum.

Physical Education.
Abstract: The present article seeks to describe the trajectory of theoretical methodological decisions and the challenges regarding the use of ethnography in a study on the daily curricular experience of a Physical Education school. It is important to highlight the process that involved the procedures to carry out the study; the implications of the choice of ethnography as a methodological theoretical reference; the initiation to ethnography; and the process of field research resulting from monitoring the curricular routine for a whole school year. It finds that ethnography enhances the understanding of the curriculum as a social construction.

Palabras clave: Etnografía.

Currículo.

Educación Física.
Resumen: Este artículo trata de narrar la trayectoria de las decisiones teóricometodológicas y de los desafíos en cuanto al uso de la etnografía en un estudio que se desarrolló en el transcurso del cotidiano curricular de un curso de Educación Física. Se destacan los procesos que involucraron los procedimientos para la realización del estudio, las implicaciones de la selección de la etnografía como marco teórico-metodológico, la iniciación a la etnografía y el proceso de investigación de campo que resultó de un año lectivo de seguimiento de la rutina curricular. Se concluye que la etnografía mejora la comprensión del currículo como una construcción social.
*Universidade Federal do Espírito Santo. Vitória, ES, Brasil. E-mail: cacaualeixo@yahoo.com.br, zenoliavix@gmail.com

Recebido em: 26-04-2017 Aprovado em: 12-09-2017

DOI: http://dx.doi.org/10.22456/1982-8918.72941 (c) (1) (9) Licence 


\section{INTRODUÇÃO}

O presente artigo, recorte de uma tese de doutorado em andamento, busca narrar a trajetória das decisões teórico-metodológicas e dos desafios acerca da escolha do uso da etnografia em um estudo que se desenvolveu no cotidiano curricular de um curso de licenciatura em Educação Física. $O$ texto possui caráter preliminar e se apresenta como uma espécie de auxílio àqueles que pretendem realizar seus estudos a partir da etnografia, principalmente no campo dos estudos curriculares da Educação Física.

Embora o foco do estudo seja o processo que envolveu a escolha da etnografia como referencial teórico-metodológico, achamos pertinente informar ao leitor que o objetivo da tese foi compreender como ocorre a (re)apropriação, a (re)interpretação e (re)invenção do currículo no cotidiano da formação a partir da reformulação curricular ${ }^{1}$ no qual os cursos de licenciatura e de bacharelado, via legislação, passaram a ter, obrigatoriamente, percursos formativos independentes.

A ideia de apresentar apenas uma parte da investigação, que normalmente ocupa um lugar de menor destaque nos artigos, vem da nossa leitura dos estudos que relacionavam a temática do currículo na Educação Física com a pesquisa etnográfica, pois o termo etnografia, em muitos casos, era apenas mencionado na seção dedicada ao método e ainda assim sem maiores detalhamentos. 0 mesmo ocorria nas pesquisas no campo da educação, no qual também se insere parte dos estudos da Educação Física.

O trabalho realizado por Tosta, Moreira e Buenicontro (2008), que investigaram como a etnografia era tratada em dissertações e teses no portal da Capes, entre os anos de 1990 e 2005, indicou que a maior parte dos estudos não possuía entendimento básico sobre a etnografia e por isso recaía em mera descrição de acontecimentos, evidenciando, assim, a necessidade de tratar este tema.

Em nosso caso, o interesse em utilizar a etnografia veio da necessidade de ampliar as análises que envolvem a temática curricular que ora privilegia a dimensão do currículo prescrito, ora a dimensão do vivido, sendo pouco estudadas nas duas dimensões, conforme afirma Macedo (2006).

Pensamos que vivenciar junto aos alunos e professores o desenvolvimento curricular (PACHECO, 2005) nos colocaria em uma posição mais próxima, portanto, privilegiada para compreender a dimensão que contempla o entre-lugar do prescrito e o vivido, entendendo que a cultura curricular é marcada por tradições, rupturas, ideologias, tensões e disputas políticas e epistemológicas.

Assim sendo, no exato momento em que decidimos por um estudo etnográfico, nos deparamos com muitas dúvidas e também com algumas angústias que permearam a nossa tomada de decisões no processo investigativo e que buscaremos apresentar a fim de contribuir com aqueles que pretendem se apropriar da etnografia nos estudos curriculares da área.

O artigo está organizado em duas partes: descrição dos procedimentos e interpretação dos procedimentos. Na primeira, apresentamos em detalhes todo o processo que envolveu a realização do estudo e tomada de decisões. Na segunda parte, destacamos: 1) as implicações

10 objetivo da reformulação curricular era fazer com que a licenciatura ganhasse terminalidade e integralidade própria em relação ao bacharelado. Isso exigiu a definição de currículos próprios da licenciatura que não se confundissem com o bacharelado (PARECER N. 009 DO 
da escolha da etnografia como referencial teórico-metodológico; 2) a iniciação ao processo etnográfico; 3) a apropriação das referências da Antropologia e; 4) a narrativa do processo de pesquisa de campo, resultante de um ano de acompanhamento da rotina curricular.

\section{DESCRIÇÃO DOS PROCEDIMENTOS}

Com 0 intuito de selecionar a instituição para a realização do estudo, fizemos opção pela Escola de Educação Física, Fisioterapia e Terapia Ocupacional (EEFFTO) da Universidade de Minas Gerais (UFMG), pois já havíamos realizado, em outro momento, uma análise documental da proposta pedagógica do curso de licenciatura em Educação Física. ${ }^{2}$ Deste modo, mantivemos o locus de investigação, mas em uma dimensão mais ampliada, que extrapola o currículo como documento.

Assim que construímos o projeto de pesquisa, demos início aos procedimentos para a obtenção de autorização do colegiado de graduação da EEFFTO para a realização da pesquisa, submissão do estudo ao Comitê de Ética, cadastro na Plataforma Brasil e negociação da nossa ida a campo.

Logo em seguida, diante de tantas disciplinas do currículo e dos vários grupos de pesquisa e extensão existentes na EEFFTO, nos deparamos com alguns questionamentos: como proceder para delimitar o que vamos observar? Vamos entrevistar alunos e professores? Em quais projetos de extensão e grupos de pesquisa vamos participar? Quanto tempo vamos disponibilizar para a realização do trabalho de campo? Pensamos que para responder essas perguntas era necessário traçar um caminho que fosse flexível, já que seria no processo de aproximação com o cotidiano curricular que teríamos melhores condições de tomar as decisões.

Pensamos que para o desenvolvimento da pesquisa de campo seria interessante acompanhar as aulas de uma turma de alunos do curso durante todo o semestre, pois assim teríamos a oportunidade de nos aproximar melhor dos sujeitos em função do tempo que passaríamos com eles. Essa ideia nos pareceu mais apropriada do que a de tentar acompanhar várias turmas de alunos e professores de diferentes períodos, já que o foco estava na qualidade das relações que poderiam ser estabelecidas.

O oitavo período nos pareceu interessante, visto que seria possível ter acesso aos estudantes em uma fase do curso em que teriam melhores condições de falar sobre o currículo que vivenciaram. Porém, acabamos selecionando o sétimo período, devido ao fato de o oitavo ter mais disciplinas optativas, o que poderia fazer com que a turma se dispersasse bastante. Além disso, a possibilidade de acompanhar o sétimo período permitiria, caso houvesse necessidade, estender a nossa observação por mais um semestre com a mesma turma.

Enviamos um e-mail a todos os professores que ministravam aulas no sétimo período do curso solicitando autorização para acompanhá-los em suas disciplinas e explicamos o objetivo do estudo e anexamos o Termo de Consentimento Livre e Esclarecido (TCLE). Alertamos os professores de que a nossa participação nas aulas poderia ser feita de forma "passiva", ${ }^{3}$ ou seja, apenas como observadora, ou então como colaboradora da disciplina, assumindo tarefas que eles achassem convenientes.

30 termo "passiva" foi usado em contraposição à possibilidade de participação nas aulas de forma mais "ativa", ou seja, como uma espécie de auxiliar dos professores. Ressaltamos que, em qualquer uma das situações, existe o pressuposto de relação entre pesquisador e grupo pesquisado, pois a simples presença do pesquisador já promove alteração no cenário investigado. 
Com exceção de dois professores que não responderam os e-mails em tempo de iniciar o trabalho de campo, todos os outros nos informaram da concordância e condições de participação no estudo.

Após o término do trabalho de campo referente ao primeiro semestre de 2016, resolvemos, na segunda metade do ano, dar continuidade ao estudo e acompanhar os alunos no oitavo período. $O$ objetivo era dar prosseguimento à realização das entrevistas que iniciamos com os alunos no sétimo período e seria mais fácil se não perdêssemos o contato com eles.

Após o primeiro semestre, também escolhemos acompanhar uma turma de primeiro período, pois ouvimos dos alunos veteranos o relato de que, no primeiro período, eles já realizavam uma avaliação do currículo a partir de suas expectativas iniciais com o curso em face daquilo que lhes era apresentado, em função da falta de informação que tinham acerca das diferenças entre o curso de licenciatura e 0 de bacharelado.

Sendo assim, acompanhamos cinco disciplinas do sétimo período, uma disciplina do oitavo e três disciplinas do primeiro período, envolvendo um total de 12 professores, pois algumas disciplinas tinham mais de um professor.

\section{ANÁLISE DOS PROCEDIMENTOS}

\subsection{Implicações da escolha da etnografia como referencial teórico-metodológico}

Inicialmente parecia-nos bastante apropriado optar pela etnografia enquanto referência teórico-metodológica pelo fato de entendermos que o trabalho de campo no qual se utilizam entrevistas, observação participante e anotações em diário de campo era a condição necessária para tal. Confessamos que, a princípio, considerávamos fazer uma pesquisa do "tipo etnográfico" assim como afirma Marli André (1995), pois as teorias que nos orientavam eram referentes às do currículo e não da Antropologia.

Segundo Marli André (1995), não existe estudo etnográfico em educação, e o que se tem feito é uma adaptação da etnografia, já que para a autora há uma diferença entre a preocupação dos etnógrafos e a dos estudiosos em educação. Numa linha de pensamento semelhante, Rocha e Eckert (2008) afirmam que o método etnográfico é específico da Antropologia e, portanto, de acordo com as autoras, quando outras ciências recorrem ao método, elas estão, na verdade, adotando alguns procedimentos técnicos da etnografia, como entrevistas e observação participante.

Ao nos aprofundarmos em estudos que se propuseram fazer uma etnografia em educação, nos deparamos com autores como Magnani (2012) e Oliveira (2013a, 2013b), que afirmavam justamente o contrário. Para eles não existem pesquisas do tipo etnográfico e sim estudos etnográficos. A justificativa da utilização do termo "tipo etnográfico" está comumente associada à ideia de que o pesquisador não permanecerá por um longo período em campo e nem busca estudar povos distantes.

Segundo Oliveira (2013a), essa ideia implica "um reducionismo simplista, por não compreender a própria dinâmica e as transformações da Antropologia, e da Etnografia, nas últimas décadas. Os nativos não são mais os mesmos, e a Etnografia também não" (OLIVEIRA, 2013a, p.170). 
Apesar de indicar que outras áreas possam utilizar a etnografia, Magnani (2012), em entrevista, alerta para o risco da utilização equivocada desta. Segundo o autor, "A expressão 'observação participante', então, virou lugar-comum; qualquer ida a campo vira observação participante" (MAGNANI, 2012, p. 175).

Na busca por mais informações acerca dessa contradição, chegamos a outros autores, como Valente (1996, p. 55), que afirma que em parte das pesquisas educacionais adeptas à etnografia "incorre-se uma confusão entre procedimentos de pesquisa e objeto de investigação". Esse equívoco também é apontado por Uriarte (2012) ao dizer que o trabalho de campo não é o mesmo que etnografia, pois geógrafos e psicólogos, por exemplo, também vão a campo e nem por isso estão fazendo etnografia.

Acerca de outros equívocos, Magnani (2012, p. 17) aponta que o método etnográfico "não se confunde nem se reduz a uma técnica; pode usar ou servir-se de várias, conforme as circunstâncias de cada pesquisa; ele é antes um modo de acercamento e apreensão do que um conjunto de procedimentos". Na mesma linha, Dauster (2003, p. 8) ressalta que "não se trata de reduzir a etnografia a uma técnica, mas, sim, tratá-la como uma opção teóricometodológica, o que já implica em conceber a prática e a descrição etnográficas ancoradas nas perguntas provenientes da teoria antropológica".

A fim de conhecer como essa discussão se apresenta nas produções acadêmicas da Educação Física, nos deparamos com o estudo de Oliveira e Daolio (2007). Os autores advertem que o entendimento da etnografia como mera descrição cultural ou então um conjunto de técnicas que permite mapear o cotidiano cultural de determinado grupo implica um reducionismo, pois a etnografia deve possibilitar compreender as dinâmicas culturais de grupos sociais.

A mera descrição cultural não garante 0 acesso ao universo complexo de significados e representações destes grupos, no máximo, ajuda-nos a conhecer certas particularidades, que não amplamente contextualizadas (sociedade como um todo), corre o risco de se constituir num relato de campo (OLIVEIRA; DAOLIO, 2007, p. 139).

Os estudos etnográficos, de acordo com Oliveira e Daolio (2007), estão amplamente presentes na Educação Física, porém, segundo os autores, apesar do cuidado na realização da pesquisa de campo, parte desses estudos apenas narra o que aconteceu e, muitas vezes, não estabelece relação com o cotidiano pesquisado, resultando em dois textos diferentes no mesmo estudo, um que toma como base as teorias e o outro a experiência de campo, sem estabelecer qualquer elo entre eles.

Após tomar contato com essa discussão sobre a possibilidade de realizar por um lado um estudo do tipo etnográfico e por outro um estudo etnográfico propriamente dito, decidimos optar por um estudo etnográfico tomando como base o argumento de Magnani (2012) de que, apesar da etnografia ter sido desenvolvida pela Antropologia, isso não impede que outras áreas possam utilizar e se apropriar deste método de trabalho desde que tenham o devido cuidado $e$ não ignorarem as teorias que lhe sustentam.

\subsection{Como começar uma etnografia?}

Encontramos em Uriarte (2012) a informação de que a etnografia possui três etapas: a formação, o trabalho de campo e a escrita. Para a autora, a formação teórica se constitui como 
uma "bagagem indispensável para ir a campo" (URIARTE, 2012, p. 5). 0 trabalho de campo, em um primeiro momento seria o registro de informações mediante o ver e o ouvir, no segundo momento, vem a sacada, quando é possível "enxergar alguma ordem nas coisas" e por fim, a mais difícil de todas, a escrita, na qual "após ter encontrado uma ordem das coisas consiste em pormos as coisas em ordem [...]” (URIARTE, 2012, p.7).

Como neófitas no campo, seguimos os momentos indicados pela autora e iniciamos a formação teórica seguindo a ideia de Magnani (2012, p. 175) de que para produzir uma etnografia é preciso antes conhecer as boas etnografias, ou seja, os clássicos.

Italo Calvino na busca por definições do que seria o clássico afirmou: "É clássico aquilo que persiste como rumor mesmo onde predomina a atualidade mais incompatível" (CALVINO, 1993, p. 15). Seguindo essa definição, pensamos que, mesmo que os clássicos da etnografia tivessem sido realizados em épocas distantes, em contextos de pesquisas muito diferentes daqueles que encontramos hoje, eles se configuram como uma espécie de indicações de caminhos já trilhados, de experiências já vividas e de dilemas já enfrentados e que, portanto, devem ser lidos sem perder de vista o contexto atual em que se desenvolve o estudo.

Nessa mesma linha de pensamento, Peirano (2008, p. 9) afirma que "Podemos, sim, voltar às monografias clássicas, para lembrar que muitas foram as estratégias de transformação da pesquisa de campo em texto, o que pode ajudar a diminuir a possível ansiedade que antecede a pesquisa".

Assim sendo, os clássicos compreendem aquelas obras ou autores que são considerados leitura obrigatória para aqueles que pretendem realizar uma investigação a partir do olhar antropológico. A partir daí surgem outras questões: quais são as etnografias clássicas? Para responder a essa pergunta teríamos que perguntar àqueles que são do campo da Antropologia ou fazem estudos a partir do olhar antropológico. Mas para quem perguntar?

Inicialmente recorremos às leituras de livros introdutórios da Antropologia, como Aprender Antropologia, de François Laplantine e Antropologia: uma introdução, de Marcone e Presotto, pois já estávamos cientes de que a etnografia não está descolada das teorias antropológicas.

A partir desses dois livros nos deparamos com uma infinidade de autores, mas insistindo na busca pelos clássicos, recorremos aos programas de pós-graduação em Ciências Sociais ou Antropologia, que ofertavam disciplinas relacionadas à etnografia. Ao buscar por referências comuns às disciplinas encontramos autores de diferentes perspectivas e que viveram e realizaram seus estudos em diferentes épocas. São eles: Franz Boas, Bronislaw Malinowski, Clifford Geertz, Lévi-Strauss, Marcel Mauss e James Clifford. É claro que outros autores foram citados nas bibliografias e que possivelmente também são considerados clássicos pelos estudiosos da área, porém iniciamos a nossa leitura por estes e, inevitavelmente, a leitura de cada um deles nos levou a outros autores, e que ainda estamos estudando, pois percebemos que não era possível concluir uma formação teórica para só então ir a campo.

Além desses autores, outras duas obras nos guiaram em nossa empreitada pela etnografia: Sociedade de esquina, de William Foote White e Corpo e Alma - Notas etnográficas de um aprendiz de boxe, de Loïc Wacquant. Já tínhamos feito a leitura dessas obras em outros momentos e que foram acionadas pela memória quando decidimos pela etnografia. 
No cenário nacional, na tentativa de encontrar os clássicos nos deparamos com um texto de apresentação de uma edição da revista Horizontes Antropológicos de 2009 de Rocha e Eckert dedicado exclusivamente à etnografia. Nesse texto as autoras informam que cinco artigos se destacam na produção da Antropologia brasileira e que foram e ainda são referência para elas e para os seus alunos que iniciam suas pesquisas neste campo. Os textos são: 0 ofício de etnólogo, ou como ter 'anthropological blues', de Roberto DaMatta; "Observando o familiar" de Gilberto Velho; "Uma incursão pelo lado 'não respeitável' da pesquisa de campo", de Tereza Pires do Rio Caldeira; "A favor da etnografia", de Marisa Peirano e por fim "O trabalho do antropólogo: olhar, ouvir e escrever", de Roberto Cardoso de Oliveira. Fizemos a leitura dos textos que inevitavelmente nos levaram à leitura de outros num movimento de busca por referências que nunca cessa.

Apesar das diferentes correntes antropológicas e dos riscos que envolvem todas as classificações, podemos dizer que nos aproximamos da Antropologia interpretativa, cujo principal pensador é Clifford Geertz. Para o autor a Antropologia é possibilidade de leitura da sociedade enquanto textos ou como análoga a textos, leitura esta que implica uma interpretação.

Além disso, assumimos a ideia de Geertz (1989, p. 4), com base em Max Weber, de que "o homem é um animal amarrado a teias de significados que ele mesmo teceu [...]" e a cultura se configura como essas teias. Sendo assim, ela não é uma ciência experimental em busca de leis, e sim à procura de significados.

Além da formação voltada para os estudos da Antropologia e, mais precisamente, para a etnografia, há outro tema importante para quem trabalha com etnografia: a concepção de linguagem. Para Peirano (2008), "o trabalho de campo se faz pelo diálogo vivo e, depois, a escrita etnográfica pretende comunicar ao leitor (e convencê-lo) de sua experiência e sua interpretação. É hora, portanto, de levar a sério a linguagem que, afinal, une etnografia e teoria de forma indelével" (PEIRANO, 2008, p. 6).

No nosso caso decidimos trabalhar com a concepção dialógica de linguagem de Bakhtin, pois o que analisamos no estudo são os discursos daqueles que vivem o cotidiano curricular. Em síntese, para Bakhtin (2008) a linguagem é dinâmica, viva, portanto não é estável nem imutável e tampouco é abstraída das relações sociais. Assim sendo, o objeto do discurso na perspectiva bakhtiniana "[...] é o ponto de interseção em que se encontram diferentes opiniões, diferentes relações de sentido" (DI FANTI, 2003, p. 98). Entendemos que a noção dialógica do discurso em que a interação com o outro é um princípio convergente para a noção de alteridade tão cara aos estudos etnográficos, até mesmo porque, assim como afirma Geertz (1989), o pesquisador só pode acessar a uma interpretação a partir do seu ponto de vista, uma interpretação de "segunda ou terceira mão".

\subsection{0 trabalho de campo: estratégias e imprevistos}

neste momento, pedimos licença ao leitor para esclarecer que temos utilizado a primeira pessoa do plural para escrever este texto visto que o estudo é resultado do esforço de orientador(a) e orientando(a). Entretanto, a partir de agora, o texto será escrito em primeira pessoa do singular, pois se refere ao trabalho de campo e por mais que este tenha sido compartilhado, a etnografia, bem como revela Goldman (2006, p. 167), é "[...] o estudo das experiências humanas a partir de uma experiência pessoal". 
Com base na afirmação de Laplantine $(2003$, p. 58) de que o trabalho de campo "[...] é a própria fonte da pesquisa" e não deve ser visto como "[...] um modo de conhecimento secundário servindo para ilustrar uma tese", iniciei essa etapa do estudo, de duração de um ano letivo, com um esforço de criação de estratégias que envolveram desde o processo de aproximação com os alunos e professores passando pelas possibilidades de formas de registro daquilo que eu vivia e até mesmo a reconsideração dessas estratégias à medida que elas pareciam não surtir o efeito esperado. Com isso, foi exigida uma postura investigativa com grande grau de abertura aos imprevistos típicos da etnografia.

O primeiro passo foi pensar estratégias de aproximação com as pessoas. Em Sociedade de esquina, aprendi com o antropólogo americano William Foote White a importância da pessoa que desempenhará o papel do informante. No meu caso, foram quatro alunas que andavam sempre juntas, que se configuraram como informantes. A minha aproximação com elas foi realizada mediante uma empatia inicial, pois desde o início elas se colocaram como pessoas dispostas a me ajudar. Eu procurava me sentar ao lado delas nas aulas, estar junto no momento do intervalo e ouvir suas dúvidas e angústias em relação ao futuro profissional. Além de me apresentarem aos outros alunos, elas também me informavam sobre o funcionamento da EEFFTO, os grupos de pesquisa, as relações entre os professores e os eventos acadêmicos e científicos.

Houve, inclusive, uma ocasião em que eu estava viajando e houve uma assembleia dos alunos para decidir se aderiam ou não à paralisação das atividades acadêmicas, em função de uma emenda constitucional proposta pelo governo acerca da redução dos gastos públicos e da reforma curricular do ensino médio. Neste episódio, uma das alunas me mandou uma mensagem dizendo "Você tinha que tá aqui!" e logo em seguida me enviou um vídeo da votação que ela tinha gravado sem que eu tivesse solicitado. Mesmo após o término do estudo, continuei mantendo contato com uma das estudantes.

A aproximação com os demais estudantes do curso, de um modo geral, foi sendo desenvolvida à medida que me conheciam e compreendiam o que eu fazia ali. Assim como fugir da polícia com os balineses em um evento de briga de galos em Bali possibilitou a Geertz ganhar a confiança dos "nativos", penso que certos episódios também colaboraram para que eu ganhasse a confiança dos alunos. Falo em episódios no plural, já que para cada grupo de pessoas a relação de confiança foi estabelecida de forma diferente.

No caso dos alunos dos últimos períodos, os veteranos, a relação foi fortalecida à medida que eles percebiam que os comentários sobre colas nas provas ou críticas tecidas acerca dos professores mencionados em conversas eram mantidos em sigilo por mim.

No caso dos calouros, a relação de proximidade foi estabelecida quando, em um evento esportivo que reunia todas as turmas da EEFFTO, eu decidi torcer por eles. Lembro-me deles me perguntarem: "Você vai torcer pra quem?" Além de torcer, também participei da "corriqueira vaquinha" de arrecadação de dinheiro para confeccionar a bandeira da turma. Neste momento, como torcedora, eu também fazia parte da equipe, e isso, para quem está tratando com pessoas que pertencem ao campo esportivo, não é algo banal, significa aceitação pelo grupo.

A relação estabelecida com os professores foi mais formal, praticamente se restringiu aos momentos das aulas, com algumas exceções. Embora todos tivessem me recebido muito bem e fizessem questão de me deixar bastante à vontade durante as aulas, eu sempre ficava 
com a impressão de que a minha presença poderia incomodá-los, afinal eu era uma estranha que estava sempre fazendo anotações no caderno de campo.

Vários fatores interferiram na relação de maior ou menor proximidade estabelecida com cada um dos professores, tais como: afinidades entre campos de pesquisa, o fato de conhecerem ou não a minha orientadora, o tempo de experiência profissional de cada professor e até mesmo características da personalidade de cada um deles. Entretanto, assim como Malinowski em Argonautas do Pacífico, ao relatar que sua presença cotidiana junto aos nativos deixou de despertar tanta curiosidade, acredito que o tempo de convivência permitiu também que eu passasse de uma presença estranha para uma presença habitual, o que ficava evidente quando os professores diziam "Eu esqueci que você estava aqui". Além disso, com alguns dos professores, foi possível, até mesmo, compartilhar das minhas angústias acerca do estudo e percebia que estavam todos muito dispostos a colaborar.

Assumindo a condição de ouvinte atenta, estabeleci uma boa relação principalmente com os alunos, que passaram a me procurar para sanar dúvidas acerca das disciplinas. Em alguns casos eu era vista, principalmente pelos alunos calouros, como uma espécie de mediadora entre eles e os professores, posição que talvez eu tenha recebido em função da capacidade, como afirma Kuschnir (2001), de conciliar múltiplas identidades para transitar entre dois mundos. No mundo dos professores e no mundo dos alunos eu não pertencia a nenhum deles, mas já havia transitado pelos dois e isso me autorizava como mediadora.

No segundo semestre, iniciei o processo de entrevistas com os alunos dos períodos finais, o que me pareceu, inicialmente, uma boa forma de registro. As perguntas compreendiam temas relacionados com os motivos da escolha do curso, os saberes elencados como mais e menos importantes na formação, as lacunas do currículo, a relação teoria e prática, a participação em grupos de pesquisa e extensão, entre outros.

Apesar de ter sido uma boa opção de registro, as conversas informais realizadas em um ambiente mais descontraído, sem o uso do gravador, foram muito mais enriquecedoras, uma vez que as entrevistas, por mais que eu tivesse esperado ter desenvolvido uma aproximação maior com os alunos para realizá-las, não deixavam de se configurar um ambiente de tensão.

Com os alunos calouros, o uso do aplicativo do WhatsApp, ${ }^{4}$ no qual eu fazia parte do grupo da turma, me colocou em uma posição privilegiada para observar e participar das conversas nas quais era comentado todo tipo de assunto. Eu podia ter acesso ao que eles falavam entre eles. Como lembra Oliveira (2013a)

\footnotetext{
Vale a pena ressaltar uma questão trazida por Barth (2000), ao chamar atenção para 0 fato de os pesquisadores darem demasiada atenção ao que os informantes falam e pouca relevância ao que eles falam entre si, quando muitas vezes residem nesses diálogos importantes elementos de compreensão da realidade analisada, mais do que nos dados obtidos por meio de entrevistas (OLIVEIRA, 2013a, p. 173).
}

Com base na ideia de perceber as sutilezas, de descrever com detalhes, eu registrava o que via e ouvia nas aulas, nos eventos acadêmicos, nos corredores e em outros espaços da EEFFTO, visto que, assim como informa Geertz (1989), é a descrição densa que permite diferenciar o tique nervoso, a piscadela feita como conspiração e a piscadela por imitação. 
No início, havia uma dificuldade em realizar o registro no caderno de campo, todavia, com o passar do tempo, desenvolvi uma forma de escrita que me permitia gastar menos tempo escrevendo, através da abreviação de palavras e criação de símbolos para identificar pessoas e acontecimentos. Isso possibilitou que eu ficasse menos tempo olhando para o caderno e mais tempo atenta à reação das pessoas e ao que acontecia ao meu redor, aumentando a qualidade dos registros no lugar da quantidade.

Assim como a ideia de desenvolver estratégias de registro no caderno de campo não foi pensada previamente, outras estratégias foram desenvolvidas ao longo do trabalho de campo devido aos imprevistos encontrados. Em contrapartida, algumas delas não foram realizadas em função de aspectos como falta de tempo, como a realização de entrevistas com professores e a participação em projetos de extensão e laboratórios. Por outro lado, entrevistas realizadas com a coordenação do colegiado e com os alunos do diretório acadêmico, bem como a participação como membro da comissão organizadora de dois eventos acadêmicos e da banca de trabalho de conclusão de curso de três alunos se constituíram como aspectos de relevância para a pesquisa.

Ao final do período dedicado à realização do trabalho de campo tive a impressão de que o tempo não foi suficiente para observar, registrar ou mesmo conversar com todas as pessoas que eu desejava. Contudo, era preciso finalizar, pois os prazos exigidos aos pesquisadores atuais não são os mesmos das missões etnográficas empreendidas por Boas ou Malinowski. Além disso, era preciso dar início ao processo da escrita, tarefa árdua que demandaria um grande esforço e que deixarei para uma próxima oportunidade.

\section{CONSIDERAÇÕES FINAIS}

Embora a etnografia não seja uma novidade no âmbito das pesquisas socioculturais da Educação Física, na área curricular, todavia, seja no ensino superior ou na educação básica, ainda nos arriscamos pouco, talvez em decorrência do receio de adentrar um novo campo de conhecimento. Por vezes, é indicada a realização da etnografia na seção dedicada ao método, mas esta acaba por ser esquecida ou pouco mencionada nas análises.

A partir da nossa incursão pela etnografia procuramos apresentar o caminho que envolveu a escolha da etnografia como referencial teórico-metodológico e com isso evidenciar alguns cuidados para que esta não seja reduzida a um mero procedimento que auxilia 0 pesquisador no trabalho de campo.

Se realizada com o devido cuidado, a etnografia possibilita potencializar a noção do currículo enquanto construção social (GOODSON, 1997). A experiência de viver o cotidiano curricular junto aos professores e alunos a partir de um olhar antropológico nos permitiu compreender melhor a dinamicidade que envolve o modo como o currículo é pensado, interpretado e vivido por professores e alunos com base nas relações que estes estabelecem com os conhecimentos, normatizações, tradições e rupturas.

Assumir a etnografia como referência significa estar sempre aprendendo. É preciso recorrer às teorias antropológicas e às etnografias clássicas. É imprescindível estar aberto aos imprevistos e ter predisposição para ouvir e compreender o outro e a partir dessa interação ser capaz de se compreender. É proibido romper com as questões éticas da pesquisa, pois nem 
tudo que você viu ou ouviu precisa ser publicado. Por fim, é importante saber que não existe apenas uma maneira de se fazer etnografia, pois é a pluralidade de olhares antropológicos que a torna tão singular.

\section{REFERÊNCIAS}

ALVES, Cláudia Aleixo. Materialização e (re) interpretação do debate epistemológico em um currículo de formação em Educação Física. 2014. 144f. Dissertação (mestrado) - Programa de Pós-graduação em Educação Física, Ufes, Vitória, 2014.

ANDRÉ, Marli Elisa Dalmazo Afonso de. Etnografia da prática escolar. Campinas: Papirus, 1995.

BAKHTIN, Mikhail Mikhailovich. Problemas da poética de Dostoiévski. Tradução Paulo Bezerra. 4. ed. Rio de Janeiro: Forense Universitária, 2008.

BRASIL. Conselho Nacional de Educação. Parecer CNE/CP 009/2001, de 8 de maio de 2001. Diretrizes Curriculares Nacionais para a Formação de Professores da Educação Básica, em nível superior, curso de licenciatura, de graduação plena. Publicado no Diário Oficial da União, Brasília, DF, 18 de jan. 2002. seção 1, p. 31.

CALDEIRA, Teresa Pires do Rio. Uma incursão pelo lado "não respeitável" da pesquisa de campo. Ciências Sociais hoje, n.1, p. 331-354, 1981.

CALVINO, Italo. Por que ler os clássicos. Tradução Nilson Moulin. São Paulo: Companhia das Letras, 1993.

DA MATTA, Roberto. "O ofício do etnólogo, ou como ter "anthropological blues"', In: NUNES, Edson de Oliveira (org.) A aventura sociológica. Rio de Janeiro: Zahar, 1978. p. 23-35.

DAUSTER, Tania. Um saber de fronteira- entre a Antropologia e a Educação. In: REUNIÃO ANUAL DA ANPED, 26. 2003, Poços de Caldas. Anais... Poços de Caldas: ANPED, 2003. Disponível em: < http://26reuniao.anped.org.br/outrostextos/setaniadauster.doc >. Acesso em: 22 dez. 2014.

DI FANTI, Maria Glória Corrêa. A linguagem em Bakhtin: pontos e pespontos. Veredas, v.7, n.1 e n.2, p.95-111, jan./dez. 2003. Disponível em: <http://www.ufff.br/revistaveredas/files/2009/12/ artigo32.pdf>. Acesso em: 30 mar. 2013.

ECKERT, Cornélia; ROCHA. Ana Luísa Carvalho da. Etnografia: Saberes e Práticas. Iluminuras, v. 9, n. 21. 2008. Disponível em: <http://seer.ufrgs.br/iluminuras/article/view/9301>. Acesso em: 15 mar. 2014.

GEERTZ, Clifford. A interpretação das culturas. Rio de Janeiro: Guanabara, 1989.

GOLDMAN, Marcio. Alteridade e experiência: antropologia e teoria etnográfica. Etnográfica, v. 10, n.1, p.161-173, 2006. Disponível em: http://www.scielo.mec.pt/pdf/etn/v10n1/v10n1a08.pdf. Acesso em: 12 mar. 2014.

GOODSON, Ivor. A construção social do currículo. Lisboa: Educa, 1997.

KUSCHNIR, Karina. Trajetória, projeto e mediação na política. In: VELHO, Gilberto; KUSCHNIR, Karina. (orgs.). Mediação, Cultura e Política. Rio de Janeiro: Aeroplano. 2001.p.139-164. 
LAPLANTINE, François. Aprender Antropologia. São Paulo: Brasiliense, 2003.

MACEDO, Elizabeth. Currículo: Política, Cultura e Poder. Currículo sem fronteiras, v.6, n. 2, p. 98-113, jul/dez, 2006. Disponível em: <http://www.curriculosemfronteiras.org/vol6iss2articles/ macedo.htm>. Acesso em: 22 jan. 2013.

MAGNANI, José Guilherme Cantor. A etnografia não é um método, não uma mera ferramenta de pesquisa..., que se pode usar de qualquer maneira. Revista de Ciências Sociais, v. 43, p. 252- 266, 2012. Disponível em: <http://www.periodicos.ufc.br/index.php/revcienso/article/view/823> . Acesso em: 20 mar. 2014.

MARCONI, Marina de Andrade; PRESOTTO, Zélia Maria Neves. Antropologia: uma introdução. 6. ed. São Paulo: Atlas, 2005.

OLIVEIRA, Amurabi. Algumas pistas (e armadilhas) na utilização da Etnografia na Educação. Educação em foco, ano 16, n. 22, p 163-183, dez. 2013a. Disponível em: http://revista.uemg.br/ index.php/educacaoemfoco/article/view/322. Acesso em: 24 jan. 2014.

OLIVEIRA, Amurabi. Por que etnografia no sentido estrito e não estudos do tipo etnográfico em educação? Revista da FAEEBA - Educação e Contemporaneidade, v. 22, n. 40, p. 69-81, jul./ dez. 2013b. Disponível em: <https://www.revistas.uneb.br/index.php/faeeba/article/view/751/524>. Acesso em: 12 fev. 2014.

OLIVEIRA, Roberto Cardoso de. O trabalho do antropólogo: Olhar, ouvir e escrever. Revista de Antropologia, v.39 n.1, p. 12-37, 1996.

OLIVEIRA, Rogério Cruz de; DAOLIO, Jocimar. Pesquisa etnográfica em Educação Física: uma (re) leitura possível. Revista brasileira Ciência e Movimento, v.15 n.1, p.137-143, 2007.

PACHECO, José Augusto. Escritos curriculares. São Paulo: Cortez, 2005.

PEIRANO, Marisa. A favor da etnografia. Rio de Janeiro, Relume Dumará, 1995.

PEIRANO, Marisa. Etnografia, ou a teoria vivida. Ponto Urbe, v. 1, n. 2, 2008. Disponível em: $<$ http://pontourbe.revues.org/1890>. Acesso em: 12 jan. 2014.

ROCHA, Ana Luisa Carvalho da; ECKERT, Cornélia. Horizontes Antropológicos, ano 15, n. 32, p. 9-20, jul./dez. 2009.

TOSTA, Sandra Pereira; MOREIRA, Heloísa; BUENICONTRO, Renata. Os usos da etnografia na pesquisa educacional. In: REUNIÃO BRASILEIRA DE ANTROPOLOGIA, 26., 2008. Porto Seguro. Anais... Porto Seguro: ABA, 2008. Disponível em: $\leq$ http://www.abant.org.br/conteudo/ ANAIS/CD Virtual_26 RBA/grupos de trabalho/trabalhos/GT\%2007/TEXTO\%20COMPLETO-\%20 SANDRA\%20TOSTA.pdf >. Acesso em: 14 mar. 2016.

URIARTE, Urpi Montoya. O que é fazer etnografia para os antropólogos. Ponto Urbe, n. 6, dez. 2012. Disponível em: <https://pontourbe.revues.org/300>. Acesso: 22 jan. 2014.

VALENTE, Ana Lúcia Eduardo Farah. Usos e abusos da antropologia na pesquisa educacional. ProPosições, v. 7, n. 2, p.54-64, julho de 1996. Disponível em: <http://periodicos.sbu.unicamp.br/ ojs/index.php/proposic/article/view/8644228>. Acesso em: 1․ mar. 2014.

VELHO, Gilberto. "Observando o familiar". In: NUNES, Edson de Oliveira (org.). A aventura sociológica. Rio de Janeiro: Zahar, 1978. p. 36-46. 
WACQUANT, Loïc. Corpo e Alma. Notas Etnográficas de um Aprendiz de Boxe. Rio de Janeiro: Relume Dumará, 2002.

WHYTE, William Foote. Sociedade de esquina: a estrutura social de uma área urbana pobre e degradada. Rio de Janeiro: Jorge Zahar , 2005. 


\section{Apoio:}

Capes; Escola de Educação Física, Fisioterapia e Terapia Ocupacional da Universidade Federal de Minas Gerais. 